\title{
Assessment of Laser Effects on Skin Rejuvenation
}

\author{
Hazhir Heidari Beigvand', Mohammadreza Razzaghi ${ }^{2}$, Mohammad Rostami-Nejad ${ }^{3}$, Majid Rezaei-Tavirani ${ }^{1}$, \\ Saeed Safari ${ }^{4}$, Mostafa Rezaei-Tavirani ${ }^{5 *}$, Vahid Mansouri ${ }^{5}$, Mohammad Hossein Heidari ${ }^{5}$ \\ ${ }^{1}$ Firoozabadi Hospital, Faculty of Medicine, Iran University of Medical Sciences, Tehran, Iran \\ ${ }^{2}$ Laser Application in Medical Sciences Research Center, Shahid Beheshti University of Medical Sciences, Tehran, Iran \\ ${ }^{3}$ Gastroenterology and Liver Diseases Research Center, Research Institute for Gastroenterology and Liver Diseases, Shahid \\ Beheshti University of Medical Sciences, Tehran, Iran \\ ${ }^{4}$ Proteomics Research Center, Department of Emergency Medicine, Shahid Beheshti University of Medical Sciences, Tehran, \\ Iran
}

${ }^{5}$ Proteomics Research Center, Faculty of Paramedical Sciences, Shahid Beheshti University of Medical Sciences, Tehran, Iran

\section{*Correspondence to Mostafa Rezaei-Tavirani, Proteomics Research Center (PRC), Darband St., Qods Sq. Tehran, Iran \\ Tel: +982122714248 \\ Email: tavirany@yahoo.com \\ Published online March 15 2020}

\begin{abstract}
Laser skin resurfacing has changed the approach of facial skin rejuvenation over the past decade. This article evaluates the laser effects on skin rejuvenation by the assessment of laser characteristics and histological and molecular changes, accompanied by the expression of proteins during and after laser-assisted rejuvenation of skin. It is important to note that different layers of skin with different cells are normally exposed to the sun's UV radiation which is the most likely factor in aging and damaging healthy skin. To identify the expression of proteins, using validated databases and reviewing existing data could reveal altered proteins which could be analyzed and mapped to investigate their expression and their different effects on cell biological responses. In this regard, proteomics data can be used for better investigation of the changes in the proteomic profile of the treated skin. Different assessments have revealed the survival and activation of fibroblasts and new keratinocytes with an increase of collagen and elastin fibers in the dermis and the reduction of matrix metalloproteinases (MMPs) and heat shock proteins (HSPs) as a result of different lowpower laser therapies of skin. There are a wide range of biological effects associated with laser application in skin rejuvenation; therefore, more safety considerations should be regarded in the application of lasers in skin rejuvenation.
\end{abstract}

Keywords: Rejuvenation; Scars; Laser; Skin aging; Laser therapy.

\section{Introduction}

Laser applications in medicine have been promoted in different fields such as dermatology, dentistry, ophthalmology, and surgery. ${ }^{1-4}$ There are many documents about the widespread use of lasers in skin treatment, especially in skin rejuvenation..$^{5-7}$ Skin aging is a natural process that occurs as people age. However, it could be accelerated by such factors as sunlight, stress, and chemicals. Skin aging is affected by numerous genetic and environmental factors that can appear as wrinkles, abnormal pigmentation, skin weakness, and telangiectasia. ${ }^{8}$ Researchers are increasingly looking for different ways to rejuvenate skin. Recently, the use of laser radiation for skin rejuvenation has become commonplace and has apparently been effective. The expansion and application of lasers and light for medical procedures based on the selective principle of photothermolysis have increased exponentially over the past two decades. The fundamental principle of this procedure is that selective heating is attained by preferential laser light absorption and heat manufacture in the target chromophore, with heat being localized to the target by pulse duration shorter than the thermal relaxation time of tissue. ${ }^{9}$ This study examines the effect of the laser beam on skin rejuvenation in different aspects and reviews the published articles in this field to present a new perspective of laser application in skin rejuvenation. The study includes the research method, skin aging phenomena, skin photoaging histology, skin aging treatment, laser features and skin aging treatment, ablative lasers, nonablative lasers, fractional lasers, Photobiomodulation (PBM) lasers, laser effects on tissues, photothermolysis, molecular aspects of laser effects in cell biology, and conclusion parts.

\section{Methods}

The search engines of Scopus, Google Scholar, and PubMed were applied to search such keywords as "Skin", Laser therapy", "Rejuvenation", "Skin Aged",

Please cite this article as follows: Heidari Beigvand H, Razzaghi M, Rostami-Nejad M, Rezaei-Tavirani M, Safari S, Rezaei-Tavirani M. Assessment of laser effects on skin rejuvenation. J Lasers Med Sci. 2020;11(2):212-219. doi:10.34172/jlms.2020.35. 
and "Proteomics". The titles in English were identified and studied in such a way that the relevant articles were selected for more evaluation and assessment. The abstracts of 155 documents were investigated and the full texts of 134 articles were selected. After the review of 134 articles, 84 documents were chosen to be included in this study.

\section{Skin Aging Phenomena}

The clinical signs of skin aging include thinning skin, cigarette paper-like wrinkles, elasticity loss, and benign overgrowth or vascular formations such as keratosis or angioma. ${ }^{10}$ These clinical signs appear by genetic factors of aging. UV irradiation induces photoaging and gravity, leading to ECM matrix changing to appear wrinkles. Therefore, these aging processes are accompanied by the phenotypic exchange in cutaneous cells as well as structural and functional changes in extracellular matrix components such as collagen, elastin, and proteoglycans, which are necessary to provide tensile strength, elasticity, and hydration to skin respectively. ${ }^{11}$ Also, they cause laxity and fragility of skin with reduced collagen syntheses and enzymatic degradation. ${ }^{12}$ The degree of skin photoaging could be classified by Fitzpatrick skin types I to IV according to its severity from few wrinkles to deep wrinkles. We should also mention the vascular pattern changes as telangiectasia. ${ }^{13}$

\section{Skin Photoaging Histology}

The chronology of histological change in skin aging indicates that events such as epidermal atrophy and reduced collagen amount and fibroblasts of dermis along with the epidermal atrophy, mainly with regards to the spinosum layer of epidermis according to prolonged cell cycles are happened. ${ }^{14}$ The number of melanocytes and Langerhans cells decreases per decade after the age of thirty. ${ }^{15}$ Subsequently, the amount of collagen and elastic fibers and also fibroblasts decreases in chronologically aged skin compared to younger skin. ${ }^{16,17}$ In postmenopausal subjects, collagen synthesis is reduced by $30 \%{ }^{18}$ However, the heterogeneity and thickness alteration of epidermis in photoaging are reported. ${ }^{19} \mathrm{An}$ increase in melanocytes and different keratinocytes and the regulation of the expression of free radicals are other consequences of photoaging histology. ${ }^{20}$ It can be generally stated that changes in the aged skin occur in the dermis and between the epidermis and the dermis. It leads to the accumulation of glycosaminoglycans and proteoglycans in the area. However, it may be due to the accumulation of metalloproteinases in hypertrophic fibroblasts and it is in contrast to the photoaged skin in which the number of inflammatory cells such as eosinophils, mast cells, and other mononuclear cells increases. ${ }^{21,22}$ Wrinkle formation may cause a reduction in collagen fibers. Mostly prominent histological feature of skin photoaging is the accumulation of elastic amorphous fibers and also thicked fibers in dermis named Solar Elastosis. ${ }^{23}$

Several biological pathways and risk factors related to skin aging are determined as; telomerase shortening, ${ }^{24,25}$ Matrix metalloproteinases (MMPs), signal transduction, ${ }^{26,27}$ oxidative stress, ${ }^{28,29}$ vascular alterations, ${ }^{30}$ cytokines alterations ${ }^{31}$ and UV radiation. ${ }^{32}$

\section{Skin Aging Treatments}

Skin aging is affected by various factors including genetics, environmental exposure (UV, xenobiotics and mechanical stress), hormonal changes, and metabolic processes (production of reactive chemicals such as reactive oxygen species, sugars, and aldehydes). All factors work together to transform the skin, its function and appearance. However, solar UV is undoubtedly a major factor responsible for skin aging. Skin aging may cause psychological side effects, leading patients to seek a suitable solution. ${ }^{33}$ Public desire to look good and young is inevitable and more than 8 million cosmetic treatments were performed in the United States in 2017. ${ }^{34}$ The treatment of photoaged skin may be classified into two categories: one is the removal of pigmentation, erythema, irregular vessels, and sebaceous changes and the other one is the improvement of skin senescence. ${ }^{35}$ The process of skin rejuvenation has been associated with aggressive elements such as peeling in the past, but in recent years the demand for non-invasive treatment of skin rejuvenation has increased dramatically. Public demand for faster healing treatments with better natural state maintenance has increased, leading to a shift in skin rejuvenation techniques at public requests.

\section{Laser Features and Skin Aging Treatment}

One of the techniques for rejuvenating the skin is to use lasers and other light beams. Lasers have been used for skin rejuvenation since $1980 .{ }^{36}$ Different wavelengths of lasers have been used to treat skin aging (see Table 1). The use of high-power lasers and skin peeling by heat generation is one of the methods for skin rejuvenation. Since this process is accompanied with side effect; the adjacent damaged tissues recover with the same mechanism of wound healing, but recently the use of low-power lasers has become commercial. Different types of lasers for skin rejuvenation are ablative lasers, non-ablative lasers, and fractional lasers (Figure 1).

\section{Ablative Lasers \\ These kinds of lasers have been used to treat scars, pigmentations, and rhytides by removing the epidermis and heating dermis (Table 2). Ablative lasers are generally used for skin resurfacing and rejuvenation. ${ }^{39}$ Ablative lasers evaporate tissue and hence are more aggressive, in contrast with the mild non-ablative lasers that leave the skin intact. However, ablative lasers reduce time of treatment and cause a more difficult recovery process, they stay the lasers that create the most dramatic}


Table 1. Two Types of Lasers With Different Wavelengths Used for Skin Rejuvenation ${ }^{37.38}$

\begin{tabular}{lccc}
\hline $\begin{array}{l}\text { Laser } \\
\text { Wavelength }\end{array}$ & $\begin{array}{c}\text { Type 1(Vascular or } \\
\text { Pigment Treatment) }\end{array}$ & $\begin{array}{c}\text { Type 2 (Skin } \\
\text { Rejuvenation) }\end{array}$ & $\begin{array}{c}\text { Special } \\
\text { Targeting }\end{array}$ \\
\hline $532 \mathrm{~nm}$ & $*$ & & General \\
\hline $585 \mathrm{~nm}$ & $*$ & General \\
\hline $595 \mathrm{~nm}$ & $*$ & General \\
$755 \mathrm{~nm}$ & $*$ & & General \\
$800 \mathrm{~nm}$ & $*$ & $*$ & General \\
\hline $1064 \mathrm{~nm}$ & $*$ & $*$ & General \\
\hline Intense pulsed & $*$ & $*$ & Teneral \\
light lasers & & $*$ & Target water \\
$1320 \mathrm{~nm}$ & & $*$ & Target water \\
\hline $1450 \mathrm{~nm}$ & & & Target \\
\hline $1540 \mathrm{~nm}$ & & & oxyhemoglobin \\
\hline Pulse dye lasers & & &
\end{tabular}

impressive. For severe facial wrinkles, pigmentation, and skin challenges, ablative lasers are often the preferred treatment. ${ }^{33}$ Non-ablative lasers penetrate into the dermis and heat the dermis without heating epidermis. These types of lasers denature dermis proteins such as collagen, and stimulate collagen synthesis and finally tighten the skin bed (Figure 2). ${ }^{39}$ The most common ablative lasers used for skin rejuvenation are $\mathrm{CO}_{2}$, erbium-doped yttrium aluminium garnet (Er:YAG), and erbium doped yttrium scandium gallium garnet.

\section{Non-ablative Lasers}

Non-ablative laser resurfacing demonstrates one of the main developments in procedural dermatology over the past decade and has become the treatment of selection for a broad range of aesthetic indications. However,

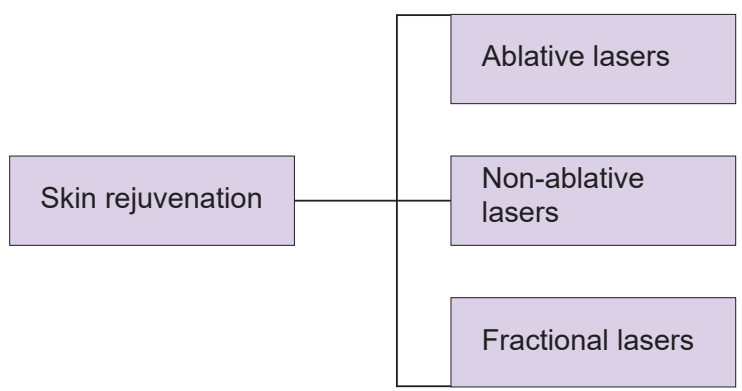

Figure 1. Different Types of Lasers Involved in Skin Rejuvenation.

safety concerns related to their use in darker skin types have remained. ${ }^{40}$ These lasers are less destructive than ablative lasers and stiffen the skin by stimulating collagen production in the dermis; the epidermis is protected through skin cooling. This type of laser is less aggressive than the optical laser and due to the stimulation of collagen in the dermis, it makes the skin firm (Table 2). The epidermis remains cool when using this laser because the waves penetrate the dermis layer. The heat generated in the dermis coagulates the collagen and then begins the wound healing process. As a result, new collagen synthesis is performed on the substrate of the skin and extracellular matrix. ${ }^{41}$ The side effects of these lasers, such as scars and infections, have decreased ${ }^{42}$; however, the efficiency of non-ablative lasers is less than ablative ones and they have been used for patients with moderate photoaging. ${ }^{43}$

\section{Fractional Lasers}

Fractional lasers including non-ablative and ablative fractional lasers generally provide columns at the depth of 1 and $2.5 \mathrm{~mm}$ into the skin, respectively. ${ }^{34}$ Non-ablative lasers influence dermis and leave epidermis with no

Table 2. The Characteristics of 3 Types of Lasers Used for Skin Rejuvenation: Er:YAG, Er:DYSGG, PPTP and Nd:YAG ${ }^{51,52}$

\begin{tabular}{|c|c|c|c|}
\hline Type of Laser & Source of Laser & Wavelength & Action \\
\hline Ablative lasers & $\begin{array}{l}\mathrm{CO}_{2} \\
\text { Er:YAG }\end{array}$ & $\begin{array}{l}10600 \mathrm{~nm} \\
2940 \mathrm{~nm} \\
2790 \mathrm{~nm}\end{array}$ & Thermally ablate and vaporize epidermis \& upper region of dermis \\
\hline $\begin{array}{l}\text { Non-ablative } \\
\text { Lasers }\end{array}$ & $\begin{array}{l}\text { ILP, } \\
\text { High dose PDL } \\
\text { Low dose PDL } \\
\text { PPTP } \\
\text { Nd:YAG } \\
\text { Diode Lasers } \\
\text { Erbium glass lasers } \\
\text { Alexandrite lasers }\end{array}$ & $\begin{array}{l}500-1299 \mathrm{~nm} \\
585-595 \mathrm{~nm} \\
589-598 \mathrm{~nm} \\
532 \mathrm{~nm} \\
1032 \& 1064 \mathrm{~nm} \\
1450 \mathrm{~nm} \\
1540 \mathrm{~nm}\end{array}$ & $\begin{array}{l}\text { Tighten the skin by collagen synthesis stimulating by the wound } \\
\text { healing process. Less destructive than ablative lasers. Heat dermis. }\end{array}$ \\
\hline $\begin{array}{l}\text { Fractional lasers } \\
\text { Ablative } \\
\text { Non-ablative }\end{array}$ & $\begin{array}{l}\text { Er:YAG } \\
\mathrm{Co}_{2} \\
\text { Erbium glass }\end{array}$ & $\begin{array}{l}2940 \mathrm{~nm} \\
10600 \mathrm{~nm} \\
1540,1550 \mathrm{~nm} \\
1440,1540,1550,1556 \mathrm{~nm} \\
1440-1540-1550-1556 \mathrm{~nm}\end{array}$ & $\begin{array}{l}\text { Create columns of beam at the depth of skin without injuries to } \\
\text { spaces between columns. Ablative fractional heat epidermis \& upper } \\
\text { dermis. Columns of Non-ablative fractional lasers heat deep dermis } \\
\text { columns }\end{array}$ \\
\hline PBM & $\begin{array}{l}\text { LEDs, lasers, broad } \\
\text { lights waves }\end{array}$ & Red \& Near infra-red wavelengths & $\begin{array}{l}\text { Treat with no thermal reactions as photophysical or photochemical } \\
\text { reaction }\end{array}$ \\
\hline
\end{tabular}

Abbreviations: Er:YAG, erbium: yttrium aluminum-garnet; Er:DYSGG, erbium-doped yttrium scandium gallium garnet; PPTP, pulsed potassium titanyl phosphate; Nd:YAG, neodymium-doped yttrium aluminum garnet; PBM, photobiomodulation; ILP, intense pulsed light; PDL, pulsed dye laser. 


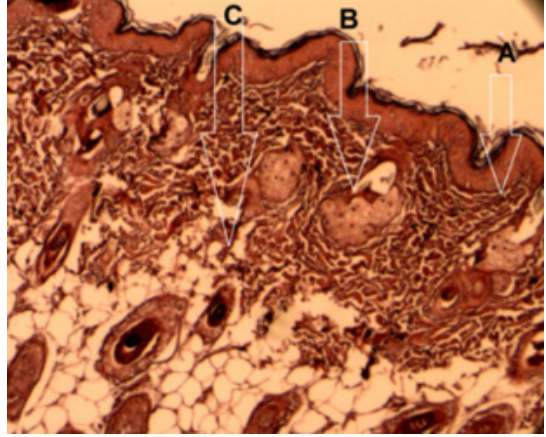

Figure 2. Penetration of Different Lasers Into the Skin for Rejuvenation (A) Ablative; (B) Non-ablative; (C) Fractional lasers. ${ }^{39}$

effects (Table 2). A comparison between the action of fractional ablative lasers and that of non-ablative ones on facial skin revealed clinical improvements in both techniques; however, collagen and elastin formation and edema in skin treated by the ablative fractional erbium laser were more than non-ablative one. ${ }^{44}$

Lasers resurfacing of skin as peeling could remove fine wrinkles of skin although, however potentially have the advantages to treat deep wrinkles by collagen making stimulation. ${ }^{45}$ Skin healing in deep peeling and laser resurfacing is known as like wound healing mechanism and depends on the depth of the lesion. ${ }^{46}$

\section{Photobiomodulation Lasers}

PBMs lasers mainly utilize red and near-red light spectra to activate biological processes used in a wide range of medical applications (Table 2). Low-power sources as LEDs, broadband lights and lasers are the sources of the photochemical and photophysical phenomenon without thermal reactions. ${ }^{47}$ Photon energy is converted to stimulate biological reactions as collagen synthesis. ${ }^{48}$ Near-infrared irradiation assists fibroblasts in making collagen to increase the consistency of skin. ${ }^{49}$ The PBM technique without thermal reactions has been able to dramatically increase patients' satisfaction with skin rejuvenation. ${ }^{50}$

\section{Laser Effects on Tissues}

Laser-skin interaction can be categorized as: photochemical, photothermal and photoplasmal pheromones. Photochemical reactions happen when the energy of photons made by the laser in the molecules of the cells causes chemical reactions in the molecules without changes in temperature. ${ }^{53}$ In photothermal reaction, photon energy absorbed in a cell and converted to heat causes an increase in the temperature of the cell, associated with denaturation and necrosis. ${ }^{53}$ Photoplasmal reaction occurs when irradiance energy is high enough $\left(10^{8}\right.$ or $\left.10^{9} \mathrm{w} / \mathrm{cm}\right)$ to form plasma accompanied by high electric fields, dielectric reactions, shock waves, and tissue rupture. ${ }^{54}$

\section{Photothermolysis}

This is a technique that targets tissue in a specific area without damaging other neighbor tissues. Different chromophores such as oxyhemoglobin, melanin, water, tattoos absorb different wavelengths. ${ }^{34}$ Longer wavelengths can penetrate in deeper parts of skin. Chromophores absorb photon energy to heat and destroy targets; however, surrounding tissues need to be cool (Thermal relaxation time). For example, the target tissue cooling time is 3 to $10 \mathrm{~ms}$ for the epidermis and $1 \mu$ s for melanosomes. ${ }^{39}$ Thus the properties of radiation and relaxation time between the periods of radiation are important for skin rejuvenation. ${ }^{55}$

\section{Molecular Aspects of Laser Effects in Cell Biology}

Several factors are proposed to illustrate the molecular basis for skin aging, including the theory of cellular senescence, decrease in cellular DNA repair capacity and loss of telomeres, point mutations of extranuclear mitochondrial DNA, oxidative stress, increased frequency of chromosomal abnormalities, single-gene mutations, reduced sugar, chronic inflammation, and so on. ${ }^{56}$ Some scientists have argued that most influences are caused by extrinsic factors and that only $3 \%$ of aging factors have an intrinsic background. ${ }^{57}$ Researches have demonstrated that low-power laser therapy can deliver lower energy to the tissues. ${ }^{58}$ The energy of low-power laser therapy could be absorbed by mitochondria and cytochrome C. ${ }^{59}$ The energy of the red-NIR (Near-infrared) laser could primarily be absorbed by mammalian cells cytochrome C oxidase. ${ }^{60}$ Excited electrons in cytochrome C oxidase lead to more electron transfer and subsequently more ATP production. ${ }^{61}$ Investigations have revealed that NO can inhibit cytochrome $\mathrm{C}$ oxidase activation; ${ }^{62}$ on the other hand, low-power lasers can inhibit NO activity, resulting in more oxidative activities of the cells. ${ }^{62,63}$ More activation of the cells causes more production of ROS. ${ }^{62,64}$ It is considered that ROS displays a necessary role in dermal extracellular matrix alterations of both intrinsic aging and photoaging. ROS can be made from various sources including the mitochondrial electron transport chain, peroxisomal and endoplasmic reticulum localized proteins, the Fenton reaction, and such enzymes as cyclooxygenases, lipoxygenases, xanthine oxidases, and nicotinamide-adenine dinucleotide phosphate oxidases. Low-power lasers are useful for the treatment of skin disorders like wrinkles, scars, and burns because low-power lasers could positively affect cell proliferation and remodeling, DNA repairing, ion channels, and membrane potentials. ${ }^{65-67}$ Low-power lasers could change the expression of different genes as the Er:YAG laser upregulates the expression of IL1B, IL8, keratin16, MMP3, and MMP $1 .^{68}$ In this regard collagen synthesis increases. Picosecond infrared laser application leads to a reduction in neighbor's tissue damage, a decrease in beta-catenin 
and TGF $b$ signaling, and more cell viability to accelerate the wound healing process. ${ }^{69}$ Ablative $\mathrm{CO} 2$ resurfacing skin revealed the upregulation of different MMPs. ${ }^{70}$ In a large-scale study of skin aging and skin rejuvenation proteins, proteomics is efficient. Proteomics has less technical limitations on protein identification and a large number of proteins could be identified by this technique. ${ }^{71}$ Proteomic analysis of foot skin compared to breast skin demonstrated the presence of 50 ECM common proteins in both skins, but there was a difference between the expressions of tenascin-x in breast skin and serum amyloid p component in foot skin. ${ }^{72}$ By examining the proteomic profile of elderly epidermis, it was found that interferonstimulating polypeptides expression increased, causing the stimulation of phosphatidylinositol 3-kinase and manganese superoxide dismutase. ${ }^{73}$ The skin irritation proteomics approach demonstrated the upregulation of HSP27 and suggested it as the skin irritation marker. ${ }^{74}$ Laser skin proteomics evaluation suggested a balance between skin cancer and laser irradiation. ${ }^{75}$ Aging leads to a reduction in skin collagen and elastic fibers with MMPs upregulation; however, UV causes skin aging effectively. ${ }^{76,77}$ A study on mouse skin exposure to the Er:YAG laser revealed skin water epidermal loss and the upregulation of p21 \& p53 to repair DNA and skin survival. ${ }^{78}$ Lowpower laser therapy could downregulate the expression of cytokeratin and antigens related to proliferation. ${ }^{79,80}$ Proteomics assay revealed the downregulation of Rho GDI 1 expression following by low-power laser therapy and the adjustment of Rho protein activities could disrupt actin cytoskeleton and kill keratinocytes following by new keratinocytes migration to replace the old ones. ${ }^{81}$ Laser therapy could reduce HSP26 protein and cause surface cell death of skin after 24 hours of treatment. ${ }^{81}$ In one study, low-level Er:YAG laser irradiation to gingival fibroblast cells caused galectin 7 wound healing protein upregulation and suggested reduced cell proliferation after laser therapy in gingival fibroblast cells. ${ }^{82}$ Lee et al reported the long-pulsed 1064-nm neodymium-doped (Nd): YAG laser treatment of mouse skin. The results of their study indicated an increase in collagen and TGF-B and decreased expression of MMPs. ${ }^{83}$ Findings from a study by De Filippis et al revealed an interaction between keratinocytes and fibroblast and overexpression of filaggrin, aquaporin, TGase, HSP70 with a reduction in MMP-1 and an increase in elastin and procollagen type1 with the use of the $1064 \mathrm{~nm} \mathrm{Nd:YAG} \mathrm{non-ablative} \mathrm{laser.}{ }^{84}$ It can be generally assumed that non-invasive lasers are effective in enhancing the activity of fibroblasts and keratinocytes with the synthesis of collagen, elastin, and decreased expression of some metalloproteinases.

\section{Conclusion}

As the assessment of skin rejuvenation and laser therapy demonstrated, many proteins related to collagen synthesis, fibroblasts and keratinocytes proliferation, and apoptosis activities were introduced. However, more investigations into the proteomic and genomic analysis are required to interpret laser effects on the molecular biology of skin rejuvenation. It is recommended to provide a comprehensive genetic and protein map which will be suitable to find out different biological pathways of laser traded skins to improve better ways to rejuvenate aged skin because many proteins and genes are still unknown. On the other hand, the improvement of lasers for the treatment of different skins and sooner cooling of skin layers is suggested. The wide range of biological events which are accompanied by laser application in skin rejuvenation implies that more safety points should be considered in the therapeutic guidelines.

\section{Ethical Considerations}

Not applicable.

\section{Conflict of Interests}

The authors declare no conflict of interest.

\section{Acknowledgment}

Shahid Beheshti University of Medical Sciences supports this research.

\section{References}

1. Rostami-Nejad M, Rezaei-Tavirani M, Zadeh-Esmaeel M-M, Rezaei Tavirani S, Akbari Z, Esmaeili S, et al. Assessment of cytokine-mediated signaling pathway dysregulation in arm skin after $\mathrm{CO} 2$ laser therapy. $J$ Lasers Med Sci. 2019 Fall;10(4):257-263. doi: 10.15171/ jlms.2019.42.

2. Asadollah FM, Mojahedi SM, Nojedehian H, Asnaashari M, Asnaashari N. The effect of Er: YAG laser irradiation combined with fluoride application on the resistance of primary and permanent dental enamel to erosion. J Lasers Med Sci. 2019;10(4):290-296. doi: 10.15171/jlms.2019.47.3.

3. Abdelkawi SA, Hassan AA, Ghoneim DF, Saif ATS. Histopathological changes of the retina after Nd: YAG laser thrombolysis in branch retinal vein occlusion: an experimental study. J Lasers Med Sci. 2019;10(1):50-55. doi: 10.15171/jlms.2019.08.

4. Khalkhal E, Rezaei-Tavirani M, Zali MR, Akbari Z. The evaluation of laser application in surgery: a review article. $J$ Lasers Med Sci. 2019;10(suppl 1):S104-S111. doi: 10.15171/ jlms.2019.S18.

5. Lee W-R, Hsiao C-Y, Huang T-H, Wang C-L, Alalaiwe A, Chen E-L, et al. Post-irradiation recovery time strongly influences fractional laser-facilitated skin absorption. Int $\mathrm{J}$ Pharm. 2019;564:48-58. doi:10.1016/j.ijpharm.2019.04.043

6. Kuroki S, Nagamine Y, Kodama Y, Kadota Y, Kouroki S, Maruta $\mathrm{T}$, et al. Intraoperative single-dose intravenous acetaminophen for postoperative analgesia after skin laser irradiation surgery in paediatric patients: a small prospective study. Turk J Anaesthesiol Reanim. 2019;47(3):192-198. doi: 10.5152/TJAR.2019.10476.

7. Agarwal M, Velaskar S. Laser Skin Rejuvenation With Fractional 1064 Q-switched Nd: YAG In 252 Patients: An 
Indian Experience. J Cosmet Dermatol. 2020;19(2):382387. doi: 10.1111/jocd.13050.

8. Knight JM, Kautz G. Sequential facial skin rejuvenation with intense pulsed light and non-ablative fractionated laser resurfacing in fitzpatrick skin type II-IV patients: A prospective multicenter analysis. Lasers Surg Med. 2019;51(2):141-149. doi: 10.1002/lsm.23007.

9. Dover JS, Hruza G. Lasers in skin resurfacing. Aust J Dermatol. 2000;41(2):72-85. doi:10.1046/j.14400960.2000.00399.x

10. Kang S, Fisher GJ, Voorhees JJ. Photoaging: pathogenesis, prevention, and treatment. Clin Geriatr Med. 2001;17(4):643-59.

11. Huertas ACM, Schmelzer CE, Hoehenwarter W, Heyroth F, Heinz A. Molecular-level insights into aging processes of skin elastin. Biochimie. 2016;128-129:163-73. doi: 10.1016/j.biochi.2016.08.010.

12. Fisher GJ, Kang S, Varani J, Bata-Csorgo Z, Wan Y, Datta $S$, et al. Mechanisms of photoaging and chronological skin aging. Arch Dermatol. 2002;138(11):1462-1470. doi:10.1001/archderm.138.11.1462

13. Han A, Chien AL, Kang S. Photoaging. Dermatologic Clinics. 2014;32(3):291-9.

14. Lavker RM. Structural alterations in exposed and unexposed aged skin. J Invest Dermatol. 1979;73(1):59-66.

15. Gilchrest BA, Blog FB, Szabo G. Effects of aging and chronic sun exposure on melanocytes in human skin. $J$ Invest Dermatol. 1979;73(2):141-3.

16. Varani J, Perone P, Warner RL, Dame MK, Kang S, Fisher GJ, et al. Vascular tube formation on matrix metalloproteinase1-damaged collagen. Br J Cancer. 2008;98(10):1646-1652. doi: 10.1038/sj.bjc.6604357

17. Braverman IM, Fonferko E. Studies in cutaneous aging: I. The elastic fiber network. J Invest Dermatol. 1982;78(5):43443.

18. Zouboulis C. Intrinsic skin aging. A critical appraisal of the role of hormones. Der Hautarzt; Zeitschrift fur Dermatologie, Venerologie, und verwandte Gebiete. Hautarzt. 2003;54(9):825-32. doi:10.1007/s00105-0030581-7

19. Kurban RS, Bhawan J. Histologic changes in skin associated with aging. J Dermatol Surg Oncol. 1990;16(10):908-14. doi:10.1111/j.1524-4725.1990.tb01554.x

20. Eller MS, Yaar M, Gilchrest BA. DNA damage and melanogenesis. Nature. 1994;372(6505):413-4. doi: 10.1038/372413a0

21. Bosset S, Bonnet-Duquennoy M, Barré P, Chalon A, Kurfurst R, Bonté F, et al. Photoageing shows histological features of chronic skin inflammation without clinical and molecular abnormalities. Br J Dermatol. 2003;149(4):82635. doi: 10.1046/j.1365-2133.2003.05456.x.

22. Schwarz T. Photoimmunosuppression. Photodermatol Photoimmunol Photomed. 2002;18(3):141-5. doi: 10.1034/j.1600-0781.2002.180307.x.

23. Tsuji T. Loss of dermal elastic tissue in solar elastosis. Arch Dermatol. 1980;116(4):474-5. doi: 10.1001/ archderm.116.4.474b.

24. Sugimoto M, Yamashita R, Ueda M. Telomere length of the skin in association with chronological aging and photoaging. J Dermatol Sci. 2006;43(1):43-7. doi: 10.1016/j. jdermsci.2006.02.004. doi: 10.1016/j.jdermsci.2006.02.004.
25. Buckingham EM, Klingelhutz AJ. The role of telomeres in the ageing of human skin. Exp Dermatol. 2011;20(4):297302. doi: 10.1111/j.1600-0625.2010.01242.x.

26. Sternlicht MD, Werb Z. How matrix metalloproteinases regulate cell behavior. Annu Rev Cell Dev Biol. 2001;17:463516. doi: 10.1146/annurev.cellbio.17.1.463.

27. Fisher GJ, Talwar HS, Lin J, Lin P, McPhillips F, Wang Z, et al. Retinoic acid inhibits induction of c-Jun protein by ultraviolet radiation that occurs subsequent to activation of mitogen-activated protein kinase pathways in human skin in vivo. J Clin Invest. 1998;101(6):1432-40. doi: 10.1172/ jci2153.

28. Rinnerthaler M, Bischof J, Streubel MK, Trost A, Richter $\mathrm{K}$. Oxidative stress in aging human skin. Biomolecules. 2015;5(2):545-89. doi: 10.3390/biom5020545

29. Son Y, Cheong YK, Kim NH, Chung HT, Kang DG, Pae HO. Mitogen-activated protein kinases and reactive oxygen species: how can ROS activate MAPK pathways? J Signal Transduct. 2011;2011:792639. doi: 10.1155/2011/792639.

30. Chung JH, Eun HC. Angiogenesis in skin aging and photoaging. J Dermatol. 2007;34(9):593-600. doi: 10.1111/j.1346-8138.2007.00341.x.

31. Borg M, Brincat S, Camilleri G, Schembri-Wismayer P, Brincat M, Calleja-Agius J. The role of cytokines in skin aging. Climacteric. 2013;16(5):514-21. doi: 10.3109/13697137.2013.802303.

32. Lee HS, Lee DH, Cho S, Chung JH. Minimal heating dose: a novel biological unit to measure infrared irradiation. Photodermatol Photoimmunol Photomed. 2006;22(3):14852. doi: 10.1111/j.1600-0781.2006.00201.x.

33. Preissig J, Hamilton K, Markus R. Current laser resurfacing technologies: a review that delves beneath the surface. Semin Plast Surg. 2012;26(3):109-16. doi: 10.1055/s-00321329413.

34. Houreld NN. The use of lasers and light sources in skin rejuvenation. Clin Dermatol. 2019;37(4):358-64. doi: 10.1016/j.clindermatol.2019.04.008.

35. Sadick NS. Update on non-ablative light therapy for rejuvenation: A review. Lasers Surg Med. 2003;32(2):120-8. doi: 10.1002/lsm.10127.

36. Anderson RR, Parrish JA. Selective photothermolysis: precise microsurgery by selective absorption of pulsed radiation. Science. 1983;220(4596):524-7. doi: 10.1126/ science.6836297.

37. Lee JH, Park SR, Jo JH, Park SY, Seo YK, Kim SM. Comparison of epidermal/dermal damage between the long-pulsed $1064 \mathrm{~nm} \mathrm{Nd:} \mathrm{YAG} \mathrm{and} 755 \mathrm{~nm}$ alexandrite lasers under relatively high fluence conditions: quantitative and histological assessments. Photomed Laser Surg. 2014;32(7):386-93. doi: 10.1089/pho.2013.3665.

38. Houreld NN. Regenerative properties of laser light. In: Quan T, editor. Molecular mechanisms of skin aging and age-related diseases. Boca Raton, FL: CRC Press; 2016. p. 182-99. doi: 10.1201/b21370.

39. Stewart N, Lim AC, Lowe PM, Goodman G. Lasers and laser-like devices: Part one. Australas J Dermatol. 2013;54(3):173-83. doi: 10.1111/ajd.12034.

40. Kaushik SB, Alexis AF. Nonablative fractional laser resurfacing in skin of color: evidence-based review. J Clin Aesthet Dermatol. 2017;10(6):51-67.

41. Griffin AC. Laser resurfacing procedures in dark-skinned 
patients. Aesthet Surg J. 2005;25(6):625-7. doi: 10.1016/j. asj.2005.09.019.

42. Henry NL, Hayes DF. Cancer biomarkers. Mol Oncol. 2012;6(2):140-6. doi: 10.1016/j.molonc.2012.01.010.

43. Goldberg DJ, Cutler KB. Nonablative treatment of rhytids with intense pulsed light. Lasers Surg Med. 2000;26(2):196200. doi: 10.1002/(sici)1096-9101(2000)26:2<196::aid$1 \mathrm{sm} 10>3.0 . \mathrm{co} ; 2-9$.

44. Borges J, Cuzzi T, Mandarim-de-Lacerda CA, ManelaAzulay M. Fractional erbium laser in the treatment of photoaging: randomized comparative, clinical and histopathological study of ablative $(2940 \mathrm{~nm})$ vs. nonablative $(1540 \mathrm{~nm})$ methods after 3 months. An Bras Dermatol. 2014;89(2):250-8. doi: 10.1590/abd18064841.20142370.

45. Meaike JD, Agrawal N, Chang D, Lee EI, Nigro MG. Noninvasive facial rejuvenation. Part 3: physician-directedlasers, chemical peels, and other noninvasive modalities. Semin Plast Surg. 2016;30(3):143-50. doi: 10.1055/s-00361584818.

46. Nguyen AT, Ahmad J, Fagien S, Rohrich RJ. Cosmetic medicine: facial resurfacing and injectables. Plast Reconstr Surg. 2012;129(1):142e-153e. doi: 10.1097/ prs.0b013e3182362c63.

47. Tsai SR, Hamblin MR. Biological effects and medical applications of infrared radiation. J Photochem Photobiol B. 2017;170:197-207. doi: 10.1016/j.jphotobiol.2017.04.014.

48. Mei XL, Wang L. Ablative fractional carbon dioxide laser combined with intense pulsed light for the treatment of photoaging skin in Chinese population: A split-face study. Medicine (Baltimore). 2018;97(3):e9494. doi: 10.1097/ MD.0000000000009494.

49. Lee JH, Roh MR, Lee KH. Effects of infrared radiation on skin photo-aging and pigmentation. Yonsei Med J. 2006;47(4):485-90. doi: 10.3349/ymj.2006.47.4.485.

50. Wunsch A, Matuschka K. A controlled trial to determine the efficacy of red and near-infrared light treatment in patient satisfaction, reduction of fine lines, wrinkles, skin roughness, and intradermal collagen density increase. Photomed Laser Surg. 2014;32(2):93-100. doi: 10.1089/ pho.2013.3616.

51. Halbina A, Trznadel-Grodzka E, Rotsztejn H. Fractional laser therapy-the next step in alleviating the symptoms of skin aging (own observations). Prz Menopauzalny. 2014;13(2):132-5. doi: 10.5114/pm.2014.42716.

52. Ichikawa H, Kanda T, Kosugi S, Kawachi Y, Sasaki H, Wakai $\mathrm{T}$, et al. Laser microdissection and two-dimensional difference gel electrophoresis reveal the role of a novel macrophage-capping protein in lymph node metastasis in gastric cancer. J Proteome Res. 2013;12(8):3780-91. doi: $10.1021 / \mathrm{pr} 400439 \mathrm{~m}$

53. Ansari MA, Erfanzadeh M, Mohajerani E. Mechanisms of laser-tissue interaction: II. Tissue thermal properties. J Lasers Med Sci. 2013;4(3):99-106. doi: 10.22037/jlms. v4i3.4681.

54. Welch AJ, Torres JH, Cheong WF. Laser physics and lasertissue interaction. Tex Heart Inst J. 1989;16(3):141-9.

55. Altshuler GB, Anderson RR, Manstein D, Zenzie $\mathrm{HH}$, Smirnov MZ. Extended theory of selective photothermolysis. Lasers Surg Med. 2001;29(5):416-32. doi: 10.1002/lsm.1136.
56. Naylor EC, Watson RE. Sherratt MJ. Molecular aspects of skin ageing. Maturitas. 2011;69(3):249-56. doi: 10.1016/j. maturitas.2011.04.011.

57. Poljšak $B$, Dahmane RG, Godić A. Intrinsic skin aging: the role of oxidative stress. Acta Dermatovenerol Alp Pannonica Adriat. 2012;21(2):33-6.

58. Sutherland JC. Biological Effects of Polychromatic Light. Photochem Photobiol. 2002;76(2):164-70. doi: 10.1562/0031-8655(2002)076<0164:beopl >2.0.co;2.

59. Huang YY, Chen ACH, Carroll JD, Hamblin MR. Biphasic dose response in low level light therapy. Dose Response. 2009;7(4):358-83. doi:10.2203/dose-response.09-027.

60. Karu TI, Kolyakov SF. Exact action spectra for cellular responses relevant to phototherapy. Photomed Laser Surg. 2005;23(4):355-61. doi: 10.1089/pho.2005.23.355.

61. Passarella S. He-Ne laser irradiation of isolated mitochondria. J Photochem Photobiol B. 1989;3(4):642-3. doi: 10.1016/1011-1344(89)80090-9.

62. Karu T. Primary and secondary mechanisms of action of visible to near-IR radiation on cells. J Photochem Photobiol B. 1999;49(1):1-17. doi: 10.1016/s1011-1344(98)00219-x.

63. Buhr K, Dugas MJ. The intolerance of uncertainty scale: Psychometric properties of the English version. Behav Res Ther. 2002;40(8):931-45. doi: 10.1016/s00057967(01)00092-4.

64. Alexandratou E, Yova D, Handris P, Kletsas D, Loukas S. Human fibroblast alterations induced by low power laser irradiation at the single cell level using confocal microscopy. Photochem Photobiol Sci. 2002;1(8):547-52. doi: 10.1039/b110213n.

65. Gilbertson DG, Duff ME, West JW, Kelly JD, Sheppard PO, Hofstrand PD, et al. Platelet-derived growth factor C (PDGF-C), a novel growth factor that binds to PDGF a and $\beta$ receptor. J Biol Chem. 2001;276(29):27406-14. doi: 10.1074/jbc.m101056200.

66. Avci P, Gupta A, Sadasivam M, Vecchio D, Pam Z, Pam $\mathrm{N}$, et al. Low-level laser (light) therapy (LLLT) in skin: stimulating, healing, restoring. Semin Cutan Med Surg. 2013;32(1):41-52.

67. Mikesh LM, Aramadhaka LR, Moskaluk C, Zigrino P, Mauch C, Fox JW. Proteomic anatomy of human skin. J Proteomics. 2013;84:190-200. doi: 10.1016/j. jprot.2013.03.019.

68. Orringer JS, Rittié L, Hamilton T, Karimipour DJ, Voorhees JJ, Fisher GJ. Intraepidermal erbium: YAG laser resurfacing: impact on the dermal matrix. J Am Acad Dermatol. 2011;64(1):119-28. doi: 10.1016/j.jaad.2010.02.058.

69. Amini-Nik S, Kraemer D, Cowan ML, Gunaratne K, Nadesan P, Alman BA, et al. Ultrafast mid-IR laser scalpel: protein signals of the fundamental limits to minimally invasive surgery. PloS One. 2010;5(9):e13053. doi: 10.1371/ journal.pone.0013053.

70. Reilly MJ, Cohen M, Hokugo A, Keller GS. Molecular effects of fractional carbon dioxide laser resurfacing on photodamaged human skin. Arch Facial Plast Surg. 2010;12(5):321-5. doi: 10.1001/archfacial.2010.38.

71. Shahrokh S, Razzaghi Z, Mansouri V, Ahmadi N. The impact of proteomic investigations on the development and improvement of skin laser therapy: A review article. J Lasers Med Sci. 2019;10(suppl 1):S90-S95. doi: 10.15171/ jlms.2019.S16. 
72. Vickers NJ. Animal Communication: When I'm Calling You, Will You Answer Too? Curr Biol. 2017;27(14):R713-R715. doi: 10.1016/j.cub.2017.05.064.

73. Gromov P, Skovgaard GL, Palsdottir H, Gromova I, Østergaard M, Celis JE. Protein profiling of the human epidermis from the elderly reveals up-regulation of a signature of interferon-gamma-induced polypeptides that includes manganese-superoxide dismutase and the p85 $\beta$ subunit of phosphatidylinositol 3-kinase. Mol Cell Proteomics. 2003;2(2):70-84. doi: 10.1074/mcp.m200051mcp200.

74. Boxman IL, Hensbergen PJ, Van Der Schors RC, Bruynzeel DP, Tensen CP, Ponec M. Proteomic analysis of skin irritation reveals the induction of HSP27 by sodium lauryl sulphate in human skin. Br J Dermatol. 2002;146(5):77785. doi: 10.1046/j.1365-2133.2002.04714.x.

75. Rezaei-Tavirani M, Rezaei Tavirani M, Zamanian Azodi M, Moravvej Farshi H, Razzaghi M. Evaluation of skin response after erbium: yttrium-aluminum-garnet laser irradiation: a network analysis approach. J Lasers Med Sci. 2019;10(3):194-99. doi: 10.15171/jlms.2019.31.

76. Takema Y, Yorimoto Y, Kawai M, Imokawa G. Age-related changes in the elastic properties and thickness of human facial skin. Br J Dermatol. 1994;131(5):641-8. doi: 10.1111/ j.1365-2133.1994.tb04975.x.

77. Wenk J, Brenneisen P, Meewes C, Wlaschek M, Peters T, Blaudschun R, et al. UV-induced oxidative stress and photoaging. Curr Problems Dermatol. 2001;29:83-94. doi: $10.1159 / 000060656$.

78. Schallreuter KU, Behrens-Williams S, Khaliq TP, Picksley SM, Peters EM, Marles LK, et al. Increased epidermal functioning wild-type p53 expression in vitiligo. Exp Dermatol. 2003;12(3):268-77. doi: 10.1034/j.1600- 0625.2003.00084.x.

79. Bailet O, Fenouille N, Abbe P, Robert G, Rocchi S, Gonthier $\mathrm{N}$, et al. Spleen tyrosine kinase functions as a tumor suppressor in melanoma cells by inducing senescencelike growth arrest. Cancer Res. 2009;69(7):2748-56. doi: 10.1158/0008-5472.CAN-08-2690.

80. Oender K, Trost A, Lanschuetzer C, Laimer M, Emberger $\mathrm{M}$, Breitenbach $\mathrm{M}$, et al. Cytokeratin-related loss of cellular integrity is not a major driving force of human intrinsic skin aging. Mech Ageing Dev. 2008;129(10):563-71. doi: 10.1016/j.mad.2008.05.008.

81. Pan TL, Wang PW, Lee WR, Fang CL, Chen CC, Huang $\mathrm{CM}$, et al. Systematic evaluations of skin damage irradiated by an erbium: YAG laser: histopathologic analysis, proteomic profiles, and cellular response. J Dermatol Sci. 2010;58(1):8-18. doi: 10.1016/j.jdermsci.2010.02.001.

82. Ogita M, Tsuchida S, Aoki A, Satoh M, Kado S, Sawabe M, et al. Increased cell proliferation and differential protein expression induced by low-level Er: YAG laser irradiation in human gingival fibroblasts: proteomic analysis. Lasers Med Sci. 2015;30(7):1855-66. doi: 10.1007/s10103-0141691-4.

83. Lee YB, Kang NH, Eun YS, Cheon MS, Kim KM, Cho BK, et al. Effects of Long-Pulsed 1,064-nm Neodymium-Doped Yttrium Aluminum Garnet Laser on Dermal Collagen Remodeling in Hairless Mice. Dermatol Surg. 2012;38(7 pt 1): 993-4. doi: 10.1111/j.1524-4725.2012.02374.x.

84. De Filippis A, Perfetto B, Guerrera LP, Oliviero G, Baroni A. Q-switched $1064 \mathrm{~nm} \mathrm{Nd-Yag} \mathrm{nanosecond} \mathrm{laser} \mathrm{effects}$ on skin barrier function and on molecular rejuvenation markers in keratinocyte-fibroblasts interaction. Lasers Med Sci. 2019;34(3):595-605. doi: 10.1007/s10103-018-2635-1. 